2014-04

\title{
Differential processing of consonants and vowels in the auditory modality: A cross-linguistic study
}

Delle Luche, C

http://hdl.handle.net/10026.1/9947

\begin{abstract}
10.1016/j.jml.2013.12.001
Journal of Memory and Language

Elsevier BV
\end{abstract}

All content in PEARL is protected by copyright law. Author manuscripts are made available in accordance with publisher policies. Please cite only the published version using the details provided on the item record or document. In the absence of an open licence (e.g. Creative Commons), permissions for further reuse of content should be sought from the publisher or author. 


\title{
Differential processing of consonants and vowels in the auditory modality: A cross-linguistic study
}

\author{
Claire Delle Luche ${ }^{\mathrm{a}, *}$, Silvana Poltrock ${ }^{\mathrm{b}, \mathrm{c}}$, Jeremy Goslin ${ }^{\mathrm{a}}$, Boris New ${ }^{\mathrm{d}, \mathrm{e}}$, \\ Caroline Floccia ${ }^{\mathrm{a}}$, Thierry Nazzi ${ }^{\mathrm{b}, \mathrm{c}}$ \\ a School of Psychology, Plymouth University, United Kingdom \\ ${ }^{\mathrm{b}}$ Université Paris Descartes, Sorbonne Paris Cité, Paris, France \\ ${ }^{\mathrm{c}}$ CNRS, Laboratoire Psychologie de la Perception, UMR 8158, Paris, France \\ ${ }^{\mathrm{d}}$ Institut Universitaire de France, Paris, France \\ ${ }^{\mathrm{e}}$ Laboratory of Psychology and Neurocognition, UMR 5105, CNRS, University of Savoie, BP 1104, F-7301 Chambéry cedex, France
}

\section{A R T I C L E I N F O}

\section{Article history:}

Received 11 December 2012

revision received 25 November 2013

Available online 25 December 2013

\section{Keywords:}

Auditory priming

Consonants and vowels

Phonological processing

Auditory word recognition

Cross-linguistic

\begin{abstract}
A B S T R A C T
Following the proposal by Nespor, Peña, and Mehler (2003) that consonants are more important in constraining lexical access than vowels, New, Araújo, and Nazzi (2008) demonstrated in a visual priming experiment that primes sharing consonants (jalu-JOLI) facilitate lexical access while primes sharing vowels do not (vobi-JOLI). The present study explores if this asymmetry can be extended to the auditory modality and whether language input plays a critical role as developmental studies suggest. Our experiments tested French and English as target languages and showed that consonantal information facilitated lexical decision to a greater extent than vocalic information, suggesting that the consonant advantage is independent of the language's distributional properties. However, vowels are also facilitatory, in specific cases, with iambic English CVCV or French CVCV words. This effect is related to the preservation of the rhyme between the prime and the target (here, the final vowel), suggesting that the rhyme, in addition to consonant information and consonant skeleton information is an important unit in auditory phonological priming and spoken word recognition.
\end{abstract}

(c) 2013 Elsevier Inc. All rights reserved.

\section{Introduction}

Consonants and vowels are described as two separate phonological categories (Ladefoged, 2001; Maddieson, 1984; but see Carré, 2009 and Stilp \& Kluender, 2010, for a unification proposal), with many differing properties: consonants are shorter and perceived more categorically; there is more variability in the production of vowels than of consonants; vowels are often harmonized within words while consonants are not (Repp, 1984). There is also neuropsychological (Caramazza, Chialant, Capasso, \& Miceli,

\footnotetext{
* Corresponding author. Address: School of Psychology, Portland Square B214, Plymouth University, Plymouth PL4 8AA, United Kingdom. Fax: $+44(0) 1752584808$.

E-mail address: claire.delleluche@plymouth.ac.uk (C. Delle Luche).
}

2000; Ferreres, López, \& China, 2003) and neurophysiological evidence (Carreiras \& Price, 2008; Carreiras, Vergara, \& Perea, 2009; Vergara-Martínez, Perea, Marín, \& Carreiras, 2011) for different brain loci involved in their processing. These fundamental differences are also reflected in the distribution of consonants and vowels in the world's languages: most languages have more consonants than vowels (Maddieson, 1984), making consonantal information more informative for word identification. Altogether, these observations led to the proposal that consonants are more important than vowels in lexical processing while vowels are more important than consonants in relation to prosodic-syntactic information (Nespor, Peña, \& Mehler, 2003). This proposal assumes that these properties of consonants and vowels are universal - supported by a language module (Bonatti, Peña, Nespor, \& Mehler, 2005, 
2007) - and therefore valid across languages regardless of linguistic specificities (for a discussion, see Bonatti et al., 2007).

The evaluation of the contribution of consonantal and vocalic information in word learning and lexical processing in adults confirms the existence of a consonantal bias across a number of languages. Regarding word learning, Creel, Aslin, and Tanenhaus (2006) demonstrated with an artificial lexicon-learning paradigm that English-speaking adults confuse newly learned words more often when they share their consonants (e.g., suba - sabo) than when they share their vowels (e.g., nasi - tagi), suggesting that consonants contribute to lexical identification to a larger extent than vowels. This consonantal advantage was not modulated by the relative ratio between consonants and vowels in the learned words, although some modulation was found with respect to segment position (e.g., a weakened consonant effect in the coda position). In another recent study on adult word learning, Havy, Serres, and Nazzi (in press) found that French-speaking adults identify an object on a screen faster when its newly learned label differs from a distracter's label by one consonant (e.g., target label /pyv/ - distracter label /tyv/) compared to when it differs by one vowel (e.g., /pos/ - /poes/). In contrast to the findings in Creel, Aslin, et al. (2006), no positional effect was found (with respect to the onset/coda difference). In sum, the interaction between the consonant bias and positional effects in these types of tasks remains rather unclear.

Moreover, when segmenting continuous speech in an artificial language, Bonatti et al. (2005) showed that French speakers are able to extract families of words when transitional probabilities highlight common consonants (e.g., / pusagi//pusegy/), but not common vowels (e.g., /pokima/ /рэьila/). The use of vocalic regularities seems privileged for the extraction of structural, grammar-like rules (see Toro, Nespor, Mehler, \& Bonatti, 2008), but not lexical cues, except in conditions allowing consecutive repetitions of the same word family (Newport \& Aslin, 2004).

Second, regarding lexical processing, classic adult word processing tasks also point to an advantage for consonantal information. In word reconstruction tasks in which an auditory pseudoword has to be transformed into a real word by changing one phoneme, listeners prefer to preserve the consonantal structure over the vocalic one, so that kebra would be changed into cobra rather than zebra. Comparable results have been observed in English (Sharp, Scott, Cutler, \& Wise, 2005; van Ooijen, 1996), Dutch and Spanish (Cutler, Sebastián-Gallés, Soler-Vilageliu, \& van Ooiken, 2000). Visual priming experiments, on the whole, also converge toward a consonantal priming effect, as attested by the results found using the relative-position (csn preceding casino is facilitatory, but not aio, Duñabeitia \& Carreiras, 2011), the delayed-letter (e.g., $b u$-b or $b$-lb as primes preceding bulb, Vergara-Martínez et al., 2011) and the replaced-letter (e.g., duvo or rifa preceding diva, New \& Nazzi, in press; New, Araújo, \& Nazzi, 2008) paradigms. On the contrary, studies using the transposed-letter paradigm (e.g., academy preceded by adacemy or acedamy, Carreiras et al., 2009; Lupker, Perea, \& Davis, 2008; Perea \& Carreiras, 2006; Perea \& Lupker, 2004) revealed a vowel advantage. However, it has been suggested that effects found in the transposed-letter paradigm are mostly due to orthographic processing (Acha \& Perea, 2010) while studies using paradigms tapping the phonological level only show a consonant advantage (see New \& Nazzi, in press, for a more detailed argument). In favor of this argument, replaced-letter experiments (New \& Nazzi, in press; New et al., 2008), where the whole consonant or vowel tier is replaced, established an advantage of consonant-related primes (e.g., duvo) for prime durations of 50 and $66 \mathrm{~ms}$, durations at which phonological effects are typically observed (Grainger \& Ferrand, 1994, 1996). No consonant advantage was observed with shorter primes (33 ms) that usually only induce orthographic priming. This series of studies (see also Berent \& Perfetti, 1995; Columbo, Zorzi, Cubelli, \& Brivio, 2003; Lee, Rayner, \& Pollatsek, 2001) suggests that the locus of this consonant bias is at the phonological rather than the orthographic level. The present study will explore another way to disentangle phonological from orthographic effects: adults were tested here in the auditory modality, which should favor the use of phonological over orthographical information.

Further insight into the mapping between phonological forms and lexical representations can be gained through infant studies. Word learning tasks with pairs of words differing by one phoneme reveal that French-learning toddlers are sensitive to consonant but not to vowel contrasts until the age of 30 months (Havy \& Nazzi, 2009; Nazzi, 2005; Nazzi \& Bertoncini, 2009; Nazzi, Floccia, Moquet, \& Butler, 2009; Nazzi \& New, 2007). Moreover, even older French-learning children and French adults show a consonant bias in word learning tasks (Havy, Bertoncini, \& Nazzi, 2011; Havy et al., in press). A comparable asymmetry is observed with a familiar word recognition task in French-learning 14-23-month-olds: a consonant change prevents word recognition, but not a vowel change (Zesiger \& Jöhr, 2011). However, results from English-learning children do not show such a pervasive consonantal bias. Indeed, while Nazzi et al. (2009) showed that 30-month-old English children give more weight to consonantal information when learning new words, Creel (2012) reported an equal sensitivity to consonant and vowel mispronunciations in familiar words in 3.5-year-old children. In addition, younger children have been found to access vocalic information as well as consonant information in lexical processing (Mani \& Plunkett, 2007, 2008) and word learning (Floccia, Nazzi, Delle Luche, Poltrock, \& Goslin, in press). This undermines the assumption of a universal consonantal bias in place at the onset of lexical acquisition. Recent work using an interactive word learning task in Danish, a language with many more vowels than consonants ( 19 consonants vs. 16 vowels, doubled with a duration contrast and 2 schwas, Bleses, Basbøll, Lum, \& Vach, 2010), revealed that Danish-learning 20-month-olds rely more on vocalic than consonantal information (Højen \& Nazzi, in preparation; Nazzi et al., 2011). This suggests that the phoneme inventory or the acoustic characteristics of a given language (e.g., consonantal lenition that makes consonants less prominent in Danish) is important in development, and might also be in adulthood.

Although these previous studies have provided considerable evidence on the relative importance of consonantal 
information in lexical processing, most adult studies have focused on visual paradigms. However, the initial proposal by Nespor et al. (2003) was mostly concerned with speech, the primary media for language processing and acquisition. Evidence from the auditory modality in adult experiments is so far mostly indirect, based on offline measures (Cutler et al., 2000; van Ooijen, 1996). Therefore, the aim of the current study was first to clarify the role of consonants and vowels at the phonological level in adults, using a direct online measure of auditory processing. This will be done with an auditory adaptation of the replaced-letter paradigm used in New et al. (2008) and New and Nazzi (in press), to provide a direct comparison with the results obtained in visual word recognition. Moreover, although no cross-linguistic differences have been observed so far in adulthood (but few have explored such a possibility), studies with children report cross-linguistic differences, calling for further evaluation of this issue in adulthood.

The second aim was therefore to shed light on the crosslinguistic differences found in the developmental literature. To do so, we will focus on French and English adult listeners, for two reasons. First, as reviewed above, these two languages led to contrastive results in developmental studies. Second, they differ on a few variables that are likely to affect the phonological processing of consonants and vowels. Not only do these languages differ regarding their consonant/vowel ratio (17-15 in French, 24-12 in English), which should give different weight to consonantal information, but English also has more consonant clusters than French (1133 vs. 545 in French, counted from CELEX and LEXIQUE respectively, Baayen, Piepenbrock, \& Gulikers, 1995; New, Pallier, Ferrand, \& Matos, 2001). Added to the fact that the English vocalic system is more complex in terms of diphthongs and contrastive features than the French one, consonants are, in theory, comparatively more informative in English than in French, so we could expect a larger consonantal bias in English. It is interesting to note however that cross-linguistic developmental evidence points to the exact opposite effect, as Frenchlearning toddlers show an earlier and more consistent consonant bias than English-learning children (Floccia et al., in press; Havy \& Nazzi, 2009; Havy et al. 2011; Mani \& Plunkett, 2007, 2008; Nazzi et al., 2009).

\section{Experiment 1: French}

In this experiment, a group of French-speaking participants was tested in a lexical decision task in which auditory targets (e.g., carreau /каво/, meaning tile) were preceded by auditory prime non-words. Like in New et al. (2008) and New and Nazzi (in press), the primes shared the same consonant tier as the targets but had different vowels (е.g., /кевø/), or shared the vowel tier but had different consonants (e.g., /ga3o/), or shared no phoneme at all (e.g., /ge3ø/). The identity priming condition (е.g., /каво/ priming / каво/) used in New et al. (2008) and New and Nazzi (in press) in the visual version of this task was excluded in this study to avoid strategic expectancies in participants (since the primes are perceptible, having a real word as a prime would have been an obvious bias).
Method

\section{Participants}

Forty-two French participants (21 females, mean age: 28 years; range: $20-44$ years) were tested at the Université René Descartes in Paris for a payment of $€ 5$. All participants reported no language or hearing impairment and were monolingual native French speakers.

\section{Stimuli and design}

The target items consisted of 48 disyllabic nouns (see Appendix 1) selected from the French LEXIQUE 3.70 database (New et al., 2001). Half of these had a phonological CVCV structure (C: Consonant; V: Vowel) and half a VCVC structure, none included diphthongs. These two word categories were balanced across a range of linguistic variables (subtitle frequency, phonological and orthographic Levenshtein distances, orthographic and phonological uniqueness points, calculated with n-watch, Davis, 2005; see Appendix 1). An additional 48 distracter words were also selected with the same proportion of $\mathrm{C}$ - and $\mathrm{V}$-initial words, but with a range of phonological structures dissimilar to those used in the test items. Ninety-six nonword targets were also generated, which had the same distribution of phonological structures as the real words. All non-words respected the phonotactic rules of French and were created with the 'trigram tool' in LEXIQUE Toolbox (New \& Pallier, 2001).

These 192 target items were preceded by three types of primes: (1) in the consonant-related condition, the consonants of the target were preserved while the vowels were minimally changed (е.g., carreau / каво/, meaning tile, is changed to /кекø/); (2) in the vowel-related condition, the vowels were preserved while the consonants were minimally changed (e.g., /каво/ - /gazo/); (3) in the unrelated condition, all phonemes were changed (е.g., /како/ - I gezø/). None of these transformations led to a real French word. Whenever possible, minimal changes consisted of a single feature change (vowels: height, place, roundedness or nasality; consonants: place, voicing or manner), but some phonemes necessitated a change of two features (17.7\% of all the changes). The total number of two-feature changes was matched across the consonant- and vowel-related conditions. To clarify, two thirds of all trials (targets and distracters) were related by their consonant or vowel tiers and one third were unrelated. This was the case for both word and non-word targets.

The auditory stimuli were recorded by a native speaker of French who was naïve to the aims of the experiment, or the link between target and primes. Recordings were conducted in a sound-attenuated booth, digitized at a rate of $22,050 \mathrm{~Hz}$ and a resolution of 16 bits.

\section{Procedure}

Three lists of 192 trials were constructed in which prime-target pairs were rotated according to a pseudo Latin-square design, so that a given target was primed by only one prime condition in each list, but by all three conditions across the three lists. Each participant was presented with a single list. Therefore, each list was presented to 14 participants. 
Participants were tested individually in a quiet, dimlylit room. Stimulus presentation and response recording were carried out using the E-Prime 1.1 software (Psychology Software Tools). Each trial began with the presentation of a fixation cross in the middle of the screen for $500 \mathrm{~ms}$. This was followed by the prime and then the target, with a $10 \mathrm{~ms}$ ISI between the two. Each trial ended $1500 \mathrm{~ms}$ after target offset, or when a response was provided by the participant. Participants were instructed to indicate the lexical nature of the second sound in each trial by pressing a button with the index finger of their dominant hand if the sound was a real word, and by pressing a button with the index finger of their non-dominant hand if it was a non-word. Twelve practice trials were presented at the beginning for warm-up purposes, each followed by feedback about accuracy and reaction times to stress the importance of both aspects. All items were presented in pseudo-randomized order, with a maximum of three words or non-words in a row. The participants could take a short break after the first block of 96 trials. The experiment lasted approximately $20 \mathrm{~min}$.

\section{Results and discussion}

The data were analyzed on the target words only (CVCV and VCVC structures). No target word had more than $23.8 \%$ of errors (range between $0 \%$ and $23.8 \%$, mean: $4.8 \%$ ) and since it satisfies the $33 \%$ limit criterion by New et al. (2008), all items were thus included in the analysis. A repeated measure ANOVA was run on reaction times measured from the onset of the target (RTs), with priming condition (consonant-related, vowel-related, and unrelated) and structure (CVCV vs. VCVC) as within-subject factors. $F$ - and $t$-values are always given by subject $\left(F_{1}\right)$ and by item $\left(F_{2}\right)$. Prior to the RT analysis, error responses $(4.76 \%)$ and outliers defined by RTs greater than 2.5 standard deviations above or below the grand mean RT (2.08\%) and 2.5 $S D$ individually (2.07\%) were discarded. A similar ANOVA was run on errors, but since none of the main effects or interaction in the error analysis were significant (all ps $>.12$ ), they are not discussed any further.

The mean RTs of each priming condition are displayed in Table 1, split by structure.

Analysis of RTs revealed a significant main effect of structure $\left(F_{1}(1,41)=139.1, p<.001, \eta^{2}=0.77 ; F_{2}(1,46)=\right.$ 9.64, $p=.003, \eta^{2}=0.17$ ) corresponding to longer RTs for CVCV words $(M=800 \mathrm{~ms})$ than for VCVC words $(M=750 \mathrm{~ms})$. There was also a significant main effect of priming condition $\left(F_{1}(2,82)=11.79, p<.001, \eta^{2}=0.22\right.$; $\left.F_{2}(2,92)=12.67, p<.001, \eta^{2}=0.21\right)$. Follow-up pairwise comparisons, using the Holm-Bonferroni procedure (Holm, 1979) to adjust for multiple comparisons (smallest $p$-value <.016; second smallest $p$-value <.025 and third $p$-value $<.05)$ were conducted. These comparisons showed that, overall, words preceded by unrelated primes were responded to more slowly $(M=790 \mathrm{~ms})$ than targets preceded by consonant-related primes $(M=757 \mathrm{~ms}$, $t_{1}(41)=4.80, p<.001$, Cohen's $d=0.74 ; \quad t_{2}(47)=4.52$, $p<.001$, Cohen's $d=0.65)$, or vowel-related primes $\left(M=773 \mathrm{~ms}, \quad t_{1}(41)=2.39, \quad p=.021\right.$, Cohen's $d=0.37$; $t_{2}(47)=2.67, p=.01$, Cohen's $\left.d=0.39\right)$. The difference
Table 1

Mean reaction times (RTs; in ms) and percentages of error (PEs) for words in Experiment 1 (French), overall and split by structure. Standard deviations are given in brackets.

\begin{tabular}{|c|c|c|c|c|c|c|}
\hline \multirow[t]{3}{*}{ Type of prime } & \multicolumn{4}{|c|}{ Structure of target } & & \\
\hline & \multicolumn{2}{|c|}{$\overline{\mathrm{CVCV}}$} & \multicolumn{2}{|c|}{ VCVC } & \multicolumn{2}{|l|}{ All } \\
\hline & RT & PE & RT & $\mathrm{PE}$ & RT & PE \\
\hline $\begin{array}{l}\text { Consonant-related } \\
(/ \text { kek } \varnothing /-/ \text { kaRo/) }\end{array}$ & $\begin{array}{l}801 \\
(89)\end{array}$ & $\begin{array}{l}4.17 \\
(8.13)\end{array}$ & $\begin{array}{l}714 \\
(79)\end{array}$ & $\begin{array}{l}3.87 \\
(6.47)\end{array}$ & $\begin{array}{l}757 \\
(79)\end{array}$ & $\begin{array}{l}4.02 \\
(5.83)\end{array}$ \\
\hline Vowel-related & 775 & 2.38 & 773 & 6.55 & 773 & 4.46 \\
\hline (/ga3o/ - /karo/) & (91) & $(4.97)$ & (84) & (10.78) & (83) & (6.37) \\
\hline $\begin{array}{l}\text { Unrelated } \\
(\mid \text { gez } \sigma \mid-(\text { karo } \mid)\end{array}$ & $\begin{array}{l}822 \\
(89)\end{array}$ & $\begin{array}{l}5.95 \\
(9.66)\end{array}$ & $\begin{array}{l}762 \\
(79)\end{array}$ & $\begin{array}{l}5.65 \\
(9.24)\end{array}$ & $\begin{array}{l}790 \\
(74)\end{array}$ & $\begin{array}{l}5.80 \\
(6.82)\end{array}$ \\
\hline
\end{tabular}

between the consonant-related and the vowel-related priming conditions was significant in the analysis by participant $\left(t_{1}(41)=2.60, p=.01\right.$, Cohen's $d=0.40 ; \quad t_{2}(47)=1.48$, $p=.14$, Cohen's $d=0.21$ ).

The interaction between priming condition and structure was also significant $\left(F_{1}(2,82)=14.89, p<.001, \eta^{2}=0.27\right.$; $\left.F_{2}(2,92)=25.08, \quad p<.001, \quad \eta^{2}=0.35\right)$. To explore this interaction, we conducted separate analyses of priming condition for CVCV and VCVC target words.

\section{VCVC words}

A one-way ANOVA revealed a significant effect of priming condition $\left(F_{1}(2,82)=25.47, p<.001, \eta^{2}=0.38 ; F_{2}(2,46)=\right.$ 21.11, $\left.p<.001, \eta^{2}=0.48\right)$. Pairwise analyses between the three priming conditions showed that RTs for the consonant-related condition ( $M=714 \mathrm{~ms})$ were significantly faster than those for the unrelated $\left(M=762 \mathrm{~ms}, t_{1}(41)=5.92\right.$, $p<.001$, Cohen's $d=0.91 ; t_{2}(23)=4.45, p<.001$, Cohen's $d=0.91)$ or vowel-related $\left(M=773 \mathrm{~ms}, t_{1}(41)=7.30\right.$, $p<.001$, Cohen's $d=1.13 ; t_{2}(23)=5.42, p<.001$, Cohen's $d=1.11$ ) conditions. There was no significant difference between the vowel-related and unrelated conditions $\left(t_{1}(41)=1.11, \quad p=.27\right.$, Cohen's $d=0.17 ; \quad t_{2}(23)=1.66$ $p=.11$, Cohen's $d=0.34$ ).

\section{CVCV words}

A significant effect of priming condition was also found $\left(F_{1}(2,82)=7.44, p=.001, \eta^{2}=0.15 ; F_{2}(2,46)=16.01, p<.001\right.$, $\left.\eta^{2}=0.41\right)$, but with a different pattern of results emerging from pairwise comparisons. Target words that were preceded by vowel-related primes $(M=775 \mathrm{~ms})$ were processed faster than those preceded by unrelated primes $(M=822 \mathrm{~ms}$, $t_{1}(41)=3.83, \quad p<.001, \quad$ Cohen's $d=0.59 ; \quad t_{2}(23)=5.76$ $p<.001$, Cohen's $d=1.18$ ), or consonant-related primes $\left(M=801 \mathrm{~ms}, \quad t_{1}(41)=2.46, \quad p=.018\right.$, Cohen's $d=0.38$; $t_{2}(23)=3.50, p=.002$, Cohen's $\left.d=0.71\right)$. The difference between the unrelated and consonant-related conditions was marginally significant in the item analysis only $\left(t_{1}(41)=1.53, p=.13\right.$, Cohen's $d=0.23 ; t_{2}(23)=1.97, p=.06$, Cohen's $d=0.40$ ).

In sum, this experiment with French listeners shows (1) a global priming effect for words preceded by related primes (e.g., /atil/ and /esyd/ prime /asid/, acide meaning acid) as compared to unrelated ones (e.g., /etyl/ - /asid/), and (2) a larger global priming effect when the consonants of the target are preserved in the prime than when the 
vowels are preserved (by subject only). For VCVC words we found similar results to that of the French visual priming study of New et al. (2008), with facilitation when consonants were preserved, but no significant priming when the vowels were preserved. However, our results for CVCV words are quite different from those previously established using visual priming, as we found a facilitatory priming effect for vowel-related primes, and one for consonant-related primes by items only, with more priming for vowel- than consonant-related primes. Before offering some explanations for this unexpected result, we first present the English data in order to determine whether this pattern is specific to French or also extends to English.

\section{Experiment 2: English}

This experiment is similar to Experiment 1, except that it used English stimuli presented to English speakers, and manipulated stress placement, which was irrelevant in French. Indeed French does not have lexical stress, although isolated words usually present final lengthening (Fletcher \& Vatikiotis-Bateson, 1994; Vaissière, 1991). On the contrary, English disyllabic words can have a trochaic (stress initial, e.g., bunny) or iambic pattern (stress final, e.g., tattoo), the trochaic pattern being predominant (Cutler \& Carter, 1987). Since it is possible that stress location has an effect on the processing of consonants and vowels, just as it does on the processing of whole syllables (Floccia, Goslin, Morais, \& Kolinsky, 2012; Sebastián-Gallés, Dupoux, Segui, \& Mehler, 1992), this experiment will examine the potential modulation of consonant and vowel priming effects as a factor of the stress pattern of the words.

\section{Method}

\section{Participants}

Forty-five adults participated (26 females, mean age: 25 years, range: $18-40$ years). All were tested at Plymouth University for a payment of $£ 4$, were monolingual native speakers of British English, and reported no language or hearing deficit.

\section{Stimuli and design}

Seventy-two disyllabic target words were selected from the CELEX database (Baayen et al., 1995) in four categories of 18 words: trochaic CVCVs, trochaic VCVCs, iambic CVCVs, and iambic VCVCs. Stimuli in each category were balanced across various linguistic variables (see Experiment 1, Appendix 2). Because there are less one-feature changes between English vowels than French ones, and to ensure that the primes were pronounceable and respected the stress placement of the target word, more two-feature changes were needed compared to the French stimuli (overall, $38.2 \%$ of the changes included two features). However, as in Experiment 1, the percentage of one and two feature changes was balanced across vowels and consonants, and also between prime and target categories.

Seventy-two distracter words and 144 non-word distracters were selected and matched with primes, following the same method and criteria as in Experiment 1. Again, two-thirds of all trials (targets and distracters) were phonologically related (either by consonants or vowels) and a third was not. Again, this was the case for both word and non-word targets.

All auditory stimuli were recorded by a native speaker of British English in a sound-attenuated booth and digitized at a rate of $44.1 \mathrm{kHz}$ and a resolution of 16 bits.

\section{Procedure}

The procedure was identical to the one of Experiment 1, except that participant responses were captured using an EPrime button-box rather than a keyboard.

\section{Results}

Responses to 14 target words reached the 33\% error cut-off and were removed from further analysis. This unexpected high number of errors is unlikely to be due to lower intelligibility of these recorded stimuli. Indeed, error rates for all 72 target words correlated positively with error rates obtained for these words in the visual modality in a non-masked word recognition task (the British Lexicon Project, Keuleers, Lacey, Rastle, \& Brysbaert, 2012), $r=.588, p<.001$. It is possible that these rejected words may have been less familiar, less imageable or had been acquired later in age, since these three factors were correlated with accuracy in Keuleers et al. (2012). Correct response rates for the remaining words averaged 87\% (from 69\% to 100\%). As in Experiment 1, RTs from erroneous responses (12.76\%) and outliers (3.49\%), defined by RTs greater than 2.5 standard deviations above or below the grand mean $(2.19 \%)$ and individual mean RT (1.30\%), were discarded. After preprocessing it was noticed that two participants did not provide data for iambic CVCV words; however, they were kept in the analysis. Both error rates and RTs were analyzed using an ANOVA with the main factors of structure, stress and priming condition.

The analyses of the error rates showed a significant 3 -way interaction of structure $\times$ priming condition $\times$ stress $\left(F_{1}(2,88)=7.13, \quad p=.001, \quad \eta^{2}=0.15 ; \quad F_{2}(2,108)=5.40\right.$, $\left.p=.006, \eta^{2}=0.09\right)$. No other effects or interactions were significant. Separate one-way ANOVAs with priming condition as within-subject factor were therefore carried out for each of the 4 cells (structure $\times$ stress). The priming effect was only significant in two conditions: for iambic CVCV words in the item analysis $\left(F_{1}(2,88)=2.48, p=.09\right.$, $\left.\eta^{2}=0.05 ; F_{2}(2,18)=3.86, p=.04, \eta^{2}=0.30\right)$ and for iambic VCVC words $\left(F_{1}(2,88)=5.12, p=.008, \eta^{2}=0.10 ; F_{2}(2,32)=\right.$ 7.32, $\left.p=.002, \quad \eta^{2}=0.31\right)$. Although consonant-related primes appeared to produce more errors (20.0\%) compared to unrelated $(11.7 \%)$ or vowel-related $(12.4 \%)$ primes, single comparisons within iambic CVCV words revealed no significant differences (because of the Holm-Bonferroni correction, the $p$-values are between .03 and .85). In iambic VCVC words there were significantly less errors with consonant-related primes $(7.3 \%)$ compared to vowel-related primes $\left(17.8 \%, t_{1}(44)=3.17, p=.003\right.$, Cohen's $d=0.47$; $t_{2}(16)=2.97, p=.009$, Cohen's $\left.d=0.72\right)$ and unrelated primes $\left(15.9 \%, t_{1}(44)=2.49, p=.02\right.$, Cohen's $d=0.37$; 
$t_{2}(16)=3.26, p=.005$, Cohen's $\left.d=0.79\right)$. Error rates in the unrelated and vowel-related conditions did not differ from each other $\left(t_{s}<1\right)$. In sum, the only significant effect on error rates is that iambic VCVC words were recognized more accurately in the consonant-related priming condition.

The mean RTs of each priming condition are displayed in Table 2, split by structure and stress pattern. $F$ - and $t$-values are again given by subject $\left(F_{1}\right)$ and by item $\left(F_{2}\right)$.

RTs were analyzed using a repeated measure ANOVA with the factors of structure (CVCV vs. VCVC), stress (iambic vs. trochaic) and priming condition (consonant-related, vowel-related and unrelated). This revealed a significant main effect of stress $\left(F_{1}(1,42)=53.79, p<.001, \eta^{2}=0.56\right.$; $\left.F_{2}(1,54)=11.09, p=.001, \eta^{2}=0.17\right)$ with trochaic words $(M=831 \mathrm{~ms})$ being responded faster to than iambic words ( $M=881 \mathrm{~ms}$ ). This difference is likely to be related to the difference in the durations of the words, as trochaic words were, on average, $651 \mathrm{~ms}$ long and iambic words $719 \mathrm{~ms}$. The main effect of priming condition was also significant $\left(F_{1}(2,86)=19.15, \quad p<.001, \quad \eta^{2}=0.31\right.$; $\left.F_{2}(2,108)=23.00, p<.001, \eta^{2}=0.30\right)$. Pairwise comparisons showed that target words were processed faster in the consonant-related $(M=829 \mathrm{~ms})$ condition than in both the vowel-related $(M=861 \mathrm{~ms})$ condition $\left(t_{1}(44)=\right.$ $4.85, p<.001$, Cohen's $d=0.72 ; t_{2}(57)=3.87, p<.001$, Cohen's $d=0.51)$, and the unrelated $(M=879 \mathrm{~ms})$ condition $\left(t_{1}(44)=5.67, p<.001\right.$, Cohen's $d=0.84 ; t_{2}(57)=6.49$, $p<.001$, Cohen's $d=0.85)$. The difference between vowel-related and unrelated conditions was also significant $\left(t_{1}(44)=2.06, p=.04\right.$, Cohen's $d=0.31 ; \quad t_{2}(57)=2.22$, $p=.03$, Cohen's $d=0.29$ ), with faster RTs in the vowel related condition. The effect of structure was only marginal in the subject analysis $\left(F_{1}(1,42)=4.08, p=.05, \eta^{2}=0.09\right.$; $F_{2}(1,54)<1$; CVCV words, $M=850 \mathrm{~ms} ;$ VCVC words, $M=862 \mathrm{~ms})$. There was a significant interaction between priming condition and structure $\left(F_{1}(2,86)=3.79, p=.03\right.$, $\left.\eta^{2}=0.08 ; F_{2}(2,108)=5.10, p=.008, \eta^{2}=0.09\right)$, and a three way interaction between those factors and that of stress $\left(F_{1}(2,86)=4.70, \quad p=.01, \quad \eta^{2}=0.10 ; \quad F_{2}(2,108)=4.29\right.$, $\left.p=.02, \eta^{2}=0.07\right)$. Further investigation of this three way interaction was made by conducting four separate oneway ANOVAs for each combination of structure (CVCV, VCVC) and stress (trochaic, iambic) with priming condition as the within-subject factor.

\section{VCVC trochaic words}

The effect of priming condition was significant $\left(F_{1}(2,88)=10.76, \quad p<.001, \quad \eta^{2}=0.20 ; \quad F_{2}(2,28)=12.05\right.$, $\left.p<.001, \eta^{2}=0.46\right)$, with pairwise analyses revealing significantly faster RTs with consonant-related primes $(M=788 \mathrm{~ms})$ than unrelated primes $\left(M=856 \mathrm{~ms}, t_{1}(44)=\right.$ $3.91, p<.001$, Cohen's $d=0.58 ; t_{2}(14)=3.95, p=.001$, Cohen's $d=1.02)$ or vowel-related primes $(M=834 \mathrm{~ms}$, $t_{1}(44)=3.13, p=.003$, Cohen's $d=0.47 ; \quad t_{2}(14)=5.26$, $p<.001$, Cohen's $d=1.36)$. The comparison between unrelated and vowel-related primes failed to reach significance $\left(t_{1}(44)=1.79, \quad p=.08, \quad\right.$ Cohen's $d=0.27 ; \quad t_{2}(14)=1.24$, $p=.23$, Cohen's $d=0.32$ ).

\section{VCVC iambic words}

There was a significant priming condition effect $\left(F_{1}(2,88)=11.30, \quad p<.001, \quad \eta^{2}=0.20 ; \quad F_{2}(2,32)=12.64\right.$, $\left.p<.001, \eta^{2}=0.44\right)$. Pairwise analyses showed that RTs in the consonant-related condition ( $864 \mathrm{~ms}$ ) were significantly faster than in the unrelated $(M=911 \mathrm{~ms}$, $t_{1}(44)=4.19, \quad p<.001$, Cohen's $d=0.62 ; \quad t_{2}(16)=3.79$, $p=.001$, Cohen's $d=0.92)$ and the vowel-related $(921 \mathrm{~ms}$, $t_{1}(44)=3.83, p<.001$, Cohen's $d=0.57, t_{2}(16)=4.36$, $p<.001$, Cohen's $d=1.06)$ conditions. There was no significant difference between unrelated and vowel related primes $\left(t_{1}(44)<1, t_{2}(16)=1.13, p=.28\right.$, Cohen's $\left.d=0.27\right)$.

\section{CVCV trochaic words}

Priming condition was found to have a significant effect on RTs in the analysis by participant $\left(F_{1}(2,88)=5.10\right.$, $\left.p=.008, \eta^{2}=0.10 ; F_{2}(2,30)=2.63, p=.09, \eta^{2}=0.15\right)$. Within subjects, pairwise comparisons revealed significantly faster RTs in the consonant-related condition $(M=$ $814 \mathrm{~ms})$ than the unrelated condition $(M=854 \mathrm{~ms}$, $t_{1}(44)=3.01, p=.004, \quad$ Cohen's $d=0.45 ; \quad t_{2}(15)=2.11$, $p=.05$, Cohen's $d=0.53)$. The difference between the consonant-related condition and the vowel-related condition ( $M=841 \mathrm{~ms})$ was marginally significant by subjects: $t_{1}(44)=2.30, \quad p=.026$, Cohen's $d=0.34 ; \quad t_{2}(15)=1.28$ $p=.22$, Cohen's $d=0.32$ (note that the significance threshold is $p=.025$ for comparison of this order with HolmBonferroni corrections). There was no significant difference between unrelated and vowel-related primes $\left(t_{1}(44)<1\right.$, $p=.33$, Cohen's $d=0.15 ; t_{2}(15)=1.07, p=.30$, Cohen's $d=0.27 t)$

Table 2

Mean reaction times (RTs; in ms) and percentages of error (PEs) for words in Experiment 2 (English), split by structure and stress

\begin{tabular}{|c|c|c|c|c|c|c|c|c|}
\hline \multirow[t]{4}{*}{ Type of prime } & \multicolumn{8}{|c|}{ Type of stress } \\
\hline & \multicolumn{4}{|c|}{$\begin{array}{l}\text { Iambic } \\
\text { Structure of target }\end{array}$} & \multicolumn{4}{|c|}{$\begin{array}{l}\text { Trochaic } \\
\text { Structure of target }\end{array}$} \\
\hline & \multicolumn{2}{|l|}{ CVCV } & \multicolumn{2}{|l|}{ VCVC } & \multicolumn{2}{|l|}{ CVCV } & \multicolumn{2}{|l|}{ VCVC } \\
\hline & RT & PE & RT & PE & RT & $\mathrm{PE}$ & RT & PE \\
\hline $\begin{array}{l}\text { Consonant-related } \\
\text { (/benu/ - /bıni/) }\end{array}$ & $\begin{array}{l}848 \\
(111)\end{array}$ & $\begin{array}{l}20.0 \\
(23.5)\end{array}$ & $\begin{array}{l}864 \\
(110)\end{array}$ & $\begin{array}{l}7.3 \\
(14.3)\end{array}$ & $\begin{array}{l}814 \\
(96)\end{array}$ & $\begin{array}{l}11.4 \\
(15.4)\end{array}$ & $\begin{array}{l}788 \\
(103)\end{array}$ & $\begin{array}{l}8.9 \\
(16.8)\end{array}$ \\
\hline Vowel-related & 838 & 12.4 & 921 & 17.8 & 841 & 14.0 & 834 & 8.0 \\
\hline$(/ \mathrm{n} \Lambda \mathrm{zi} /-/ \mathrm{b} \Lambda \mathrm{ni} /)$ & $(120)$ & $(23.2)$ & (89) & $(21.0)$ & $(112)$ & $(17.3)$ & (99) & $(13.8)$ \\
\hline Unrelated & 903 & 11.7 & 911 & 15.9 & 854 & 16.2 & 856 & 12.4 \\
\hline$(/$ nezu/ - /bıni/) & (113) & (15.3) & $(90)$ & (18.8) & $(128)$ & $(14.3)$ & $(100)$ & $(18.2)$ \\
\hline
\end{tabular}




\section{CVCV iambic words}

The effect of priming condition was significant $\left(F_{1}(2,86)=6.38, p=.003, \eta^{2}=0.13 ; F_{2}(2,18)=12.23, p<\right.$ $\left..001, \eta^{2}=0.58\right)$. Pairwise analyses revealed significantly faster RTs in the vowel-related condition $(M=838 \mathrm{~ms})$ than in the unrelated condition $\left(M=903 \mathrm{~ms}, t_{1}(43)=2.85\right.$, $p=.007$, Cohen's $d=0.43 ; t_{2}(9)=4.62, p=.001$, Cohen's $d=1.46)$. RTs for consonant-related primes $(M=848 \mathrm{~ms})$ were also significantly faster than RTs for unrelated primes $\left(t_{1}(43)=2.98, p=.005\right.$, Cohen's $d=0.45 ; t_{2}(9)=5.80$, $p<.001$, Cohen's $d=1.83)$. However, there was no difference between the vowel- and consonant-related conditions $\left(t_{1}(42)<1, p=.65\right.$, Cohen's $d=0.07 ; t_{2}(9)=1.22, p=.25$, Cohen's $d=0.38$ ).

These results show that consonant priming has a facilitatory effect on lexical decision latencies for all 4 tested stimulus types. In contrast, the facilitatory effect of vowel priming was only found to be significant in iambic CVCV stimuli. A clear consonant advantage was found overall, and in the two VCVC conditions, while a smaller consonant effect was found for CVCV trochaic words, and a reversed vocalic advantage was found for CVCV iambic words.

\section{Comparing the French and English data}

To compare priming effects in French (Experiment 1) and English (Experiment 2), we conducted an ANOVA on relative RTs, which are, for each language respectively, the priming effect obtained by subtracting consonant-related and vowel-related RTs from unrelated RTs (Fig. 1). A positive value signals a facilitatory effect, and a negative value signals an inhibitory effect. Since our French stimuli were recorded in isolation, they were "iambic-like" (Fletcher \& Vatikiotis-Bateson, 1994; Jun \& Fougeron, 2002; Vaissière, 1991), as our acoustic measures show (Appendix 1, Section 4). Thus, they were compared to iambic English target words only. For visual comparison purposes, we have also added the results for the English trochaic words. The ANOVA included priming condition (consonant-related vs. vowel-related) and structure (CVCV vs. VCVC) as within-subject factors and language as a between-subject factor.

There was a significant main effect of language in the subject analysis $\left(F_{1}(1,42)=4.66, \quad p=.04, \quad \eta^{2}=0.10\right.$; $\left.F_{2}(1,71)<1\right)$, with overall more facilitation in English $(M=40 \mathrm{~ms})$ than in French $(M=26 \mathrm{~ms})$. There was a main effect of structure $\left(F_{1}(1,42)=6.24, \quad p=.02, \quad \eta^{2}=0.13\right.$; $\left.F_{2}(1,71)=7.83, p=.006, \eta^{2}=0.10\right)$, with more facilitation in CVCV words $(M=48 \mathrm{~ms})$ compared to VCVC words $(M=19 \mathrm{~ms})$. There was also a significant effect of priming condition $\left(F_{1}(1,42)=13.33, p<.001, \eta^{2}=0.24 ; F_{2}(1,71)=\right.$ $\left.11.18, p=.001, \eta^{2}=0.14\right)$, with consonant-related primes showing a larger priming effect $(M=44 \mathrm{~ms})$ than vowel-related ones $(M=22 \mathrm{~ms})$. The only significant interaction was between structure and priming condition $\left(F_{1}(1,42)=\right.$ 25.62, $p<.001, \eta^{2}=0.38 ; F_{2}(1,71)=52.10, p<.001, \eta^{2}=$ 0.42 ). This interaction was further analyzed for CVCV and VCVC words separately. The effect of priming condition was significant for VCVC words $\left(t_{1}(86)=6.76, p<.001\right.$, Cohen's $d=0.72 ; t_{2}(40)=7.03, p<.001$, Cohen's $\left.d=1.10\right)$, with more priming for consonant-related primes $(M=47 \mathrm{~ms})$ than for vowel-related primes $(M=-10 \mathrm{~ms})$. For CVCV words, the effect of priming condition was significant by item only $\left(t_{1}(85)=1.17, p=.24\right.$, Cohen's $d=0.13$; $t_{2}(33)=3.51, p=.001$, Cohen's $\left.d=0.60\right)$, with more priming for vowel-related primes $(M=56 \mathrm{~ms})$ than for consonantrelated primes $(M=40 \mathrm{~ms})$. The remaining interactions were non-significant: language $\times$ structure $\left(F_{1}(1,42)<1\right.$; $\left.F_{2}(1,71)=2.40, p=.13, \eta^{2}=.03\right)$, language $\times$ priming condition $\left(F_{1}(1,42)=1.48, \quad p=.23 \quad \eta^{2}=0.03 ; \quad F_{2}(1,71)=1.73\right.$, $\left.p=.19, \eta^{2}=0.02\right)$, and language $\times$ structure $\times$ priming condition $\left(F_{1}(1,42)<1 ; F_{2}(1,71)<1\right)$.

To sum up, for iambic (English) or iambic-like (French) VCVC words, a consonant priming advantage was observed, while for CVCV words the advantage was for vowel-related priming (by items only). Although more

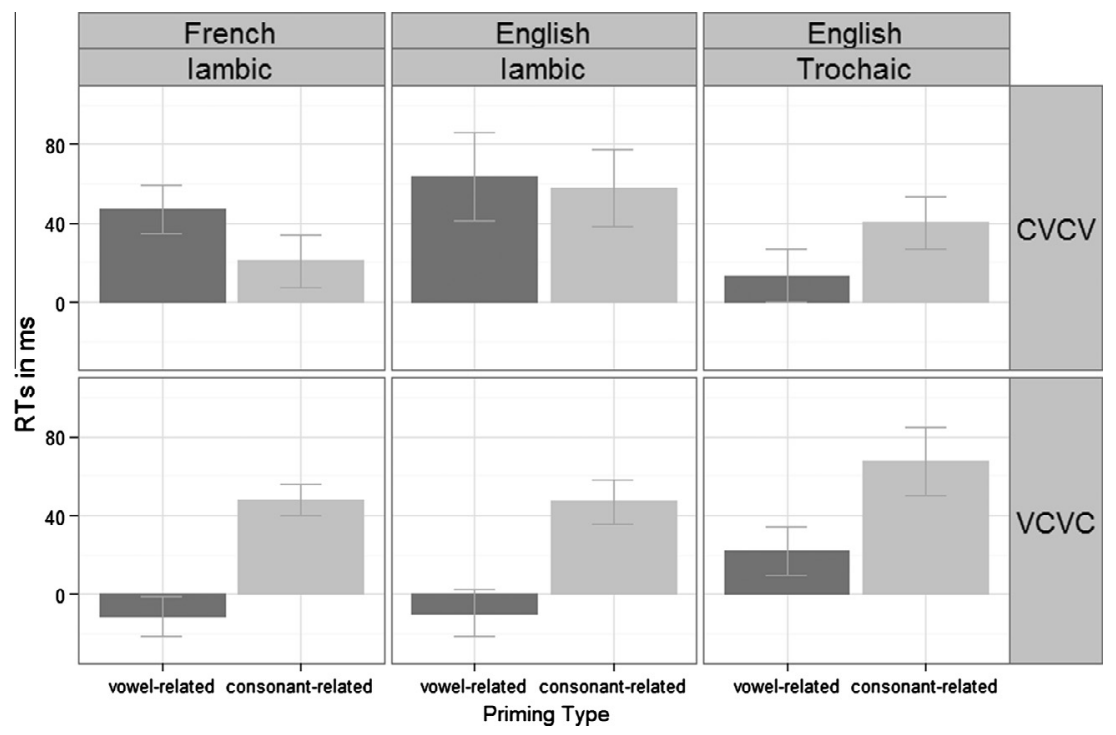

Fig. 1. Consonant and vowel priming effects (in ms) for French and English CVCV and VCVC words (Experiments 1 and 2). 
priming (in the subject analysis only) was found in English than French, the language factor did not interact with the other factors, hence the overall larger priming in English did not translate into differences in consonant- or vowelrelated priming across languages. In fact, no differences were found between the two languages when comparing words of similar syllabic and stress structures.

\section{Interim discussion}

The pattern of results in the English and French experiments is twofold. On the one hand, results confirmed that overall, consonant-related primes facilitate processing compared to unrelated primes. This was found across all stimuli used in these experiments and is in accordance with the literature (e.g., Duñabeitia \& Carreiras, 2011; New et al., 2008). On the other hand, the effect of vocalic information appeared to be modulated by structure (and stress in the case of English). Iambic-like CVCV words in French and iambic CVCV words in English were processed faster when preceded by vowel-related than unrelated primes, an effect not observed in the visual priming equivalent of the present study (New \& Nazzi, in press; New et al., 2008). In French, this resulted in an overall consonant bias (significant by subject only), which was however modulated by structure: a predicted significant consonant bias with VCVC words, compared to an unpredicted vocalic bias with CVCV words. In English, we also found this overall consonant bias and its modulation by structure, with an additional effect of stress. As such, we obtained the predicted significant consonant bias with VCVC words (trochaic and iambic) and with CVCV trochaic words in the subject analysis. For CVCV iambic words however, both consonant- and vowel-related primes unexpectedly facilitated lexical decision to the same degree.

Hence while overall the data of Experiments 1 and 2 support a consonant bias that was obtained for the first time in an online auditory task, and found for both French and English, they identify two sub-categories of words that do not follow the predicted pattern: CVCV iambic-like French words, and CVCV iambic English words. What could explain the unpredicted pattern found for these categories of words?

First, we explored the possibility that differences in intelligibility might account for these findings. Differences in stress may affect the confusability of the phonemes (Creel, Tanenhaus, \& Aslin, 2006), such that stressed vowels would be less confusable. In the case of English iambic CVCV words and iambic-like French CVCV words, the final vowel would thus be particularly well processed, which might account for the vocalic facilitation observed. However, post hoc experiments (see Appendix 1, Section 5 for French, and 2, Section 6 for English) showed that native speakers judged the stimuli just as intelligible, whether they were consonant- or vowel-related primes, iambic or trochaic words, and independently of their structure. Vowel-related priming effects should therefore not be attributed to a more perceptible final vowel in French and iambic English CVCV vowel-related words.

A second explanatory factor that we considered is ambisyllabicity, a major component of English syllabification
(Ladefoged, 2001; Lahiri, 2001). Words can be ambisyllabic when the intervocalic consonant is shared between syllables (Kahn, 1976), and it can be partly driven by the nature of the first vowel (Treiman, Bowey, \& Bourassa, 2002). Both theory (e.g., Hooper, 1972; Kahn, 1976; Pulgram, 1970) and practice (Treiman \& Danis, 1988) suggest that stress can also modulate syllabification, with intervocalic consonants being drawn to the stressed syllable. Thus, in iambic targets, the default syllabification of CV.CV and V.CVC should be reinforced as iambs are hardly prone to ambisyllabicity (Trammell, 1993), while in trochaic targets, ambisyllabicity would increase the prevalence of CVC.V and VC.VC syllabification. Based on ambisyllabicity, the modulating effect of stress upon the consonant bias should be found in both CVCV and VCVC words, yet in our data, it was only found on CVCV words. It should also be noted that the unexpected vowel-related priming effect was found in iambic(-like) CVCV words in both French and English, yet there is no evidence of ambisyllabicity in French (e.g., Goslin \& Floccia, 2007). These arguments suggest that ambisyllabicity alone cannot provide a satisfying explanation for our pattern of results.

In our third approach we investigated the possibility that the facilitatory effect found with vowel-related primes in these two sub-categories of words (CVCV iambic-like French words, and CVCV iambic English words), rather than being due to vowels per se, might be due to rhyme priming. The rhyme of a word corresponds to its stressed vowel and all subsequent phones, e.g., -unny in bunny. In our experiments, the only priming conditions where the entirety of the rhyme of the target was preserved was in the vowel-related primes of iambic CVCV words, as in this case the rhyme is simply the final vowel of the word (CVCV). In all other targets the rhyme contains both consonants and vowels (trochaic CVCV; iambic VCVC; trochaic VCVC), and therefore cannot be primed in its entirety in either the vowel- or consonant-preserved priming conditions. Therefore, a possible interpretation of our pattern of findings is that priming is observed either when consonants are preserved, or when the rhyme is preserved. This would result in a consonant bias in all conditions apart from those in which the rhyme is preserved. Where the rhyme was preserved this would result in either a vocalic bias (such as in iambic-like CVCV French words where only vowel priming is observed), or in a lack of bias (as in iambic CVCV English words where both vowel and consonant priming are found), dependent upon the relative strength of the two priming effects.

What evidence do we have of rhyme priming? Auditory priming studies (e.g., Dumay \& Radeau, 1997; Dumay et al., 2001; Radeau, 1995; Radeau, Morais, \& Segui, 1995; Slowiaczek, McQueen, Soltano, \& Lynch, 2000) have found, with monosyllabic words (CVC and even CV words) that participants are faster when there is an overlap between prime and target in the final phonemes. While this effect has been discussed as a syllable rime effect, it can also be seen as a rhyme effect since both levels are confounded in monosyllabic words. In disyllabic words, there is evidence that the consonant preceding the rhyme also needs to be preserved for priming to occur (Emmorey, 1989). Importantly, this effect seems to be specific to the auditory modality 
(Radeau et al., 1995), which could explain why it was not reported in studies similar to ours conducted in the visual modality (New \& Nazzi, in press; New et al., 2008).

In Experiment 3, we explored the possibility that a rhyme bias accounts for the vowel priming found in Experiments 1 and 2. Specifically, we examined whether a consonant bias can be observed when controlling for the rhyme overlap between the primes and the targets in the consonant- and vowel-related conditions.

\section{Experiment 3}

In Experiment 3, we focused on the word structures which resulted in unexpected vowel priming effects in Experiment 1, namely words starting with a consonant. The experiment was conducted in French only for two reasons. First, the strongest unexpected priming effects were observed in French. Second, it turned out to be impossible to design such an experiment in English due to an insufficient number of stress final CVCVCV words (e.g., kedgeree, most of which being moreover very infrequent).

Half of the target stimuli were the CVCV words used in Experiment 1. Crucially though, the consonant- and vowelrelated primes were both constructed with an additional final syllable (CV.CV) overlap with the target. This meant that the rhyme of the target was always preserved, while ensuring that the percentage of overlap between prime and target was the same in both conditions (75\%, similar to the overlap in Bedoin \& Krifi, 2009). Therefore, a target word like carreau /каво/, tile, could be preceded by its vowel-related prime (е.g., / Даво/) or its consonant-related prime (е.g., / Кево/), with the final syllable /-во/ remaining unchanged. The consonant- and vowel-related conditions were compared to an unrelated priming condition in which only the final syllable (е.g., /дево/) was preserved, which allowed us to evaluate consonant and vowel priming. We also included another unrelated condition in which the final syllable was not preserved (e.g., /de3ø/) to evaluate rhyme (or final syllable) priming effects.

Due to the higher percentage of prime-target overlap in these stimuli (75\%) which differed in only a single phoneme, additional trisyllabic CVCVCV stimuli were also included. In these CVCVCV stimuli the degree of overlap falls to $66 \%$, closer to the $50 \%$ overlap seen in Experiments 1 and 2, and thus should potentially lead to more comparable priming modulation. See Table 3 for a representation of the four experimental conditions.

A rhyme bias should lead to faster reaction times in the rhyme-related condition (technically, it is a final-syllablerelated condition) as compared to the unrelated condition. Most importantly, with rhyme preservation in both voweland consonant-related primes we should now expect to see a clear consonant bias effect leading to faster reaction times in the consonant-related condition as compared to both the vowel-related and the rhyme-related conditions. These predictions are expected to hold in trisyllabic words. However, for disyllabic words we predict there may well be smaller, possibly non-significant, effects due to the smaller number of phonemes manipulated between the different priming conditions than for the trisyllabic words.

Note that unlike Experiments 1 and 2, where we contrasted consonant-initial and vowel-initial words, in this experiment all critical words started with a consonant. Given that the consonant bias in English trochaic words was not modulated by phoneme position (CVCV vs. VCVC) there was no further motivation in contrasting this factor.

\section{Method}

\section{Participants}

Forty native French participants ( 29 females, mean age: 24 years; range: $18-45$ years) who did not participate in Experiment 1 were tested at the Université René Descartes in Paris and paid $€ 5$. They reported no language or hearing impairment.

\section{Stimuli and design}

The test stimuli consisted of the 24 CVCV words from Experiment 1, along with 24 CVCVCV words that were selected from the French LEXIQUE 3.70 database (New et al., 2001). Because of differences in their numbers or phonemes, di- and trisyllabic words could only be matched for cumulated frequency (see Appendix 3).

Primes were derived from their targets and were used to create four experimental conditions: (1) in the consonant-related condition, primes shared the final syllable and the consonant(s) (е.g., carreau /каво/, tile, was changed to /кево/, and cinéma /sinema/, meaning cinema, was changed to /synøma/); (2) in the vowel-related condition, primes shared the final syllable and the vowel(s) (e.g., /даво/ and / timema/); (3) in the rhyme-related condition, the primes shared only the last syllable (е.g., / /еко/ and /tymøma/); (4) in the unrelated condition finally, the primes shared no phoneme with the target (e.g., /de3ø/ and /tymøbs/). No phoneme change led to a real word, and minimal phonetic feature changes were applied with a method similar to Experiments 1 and 2. Distracter words were $48 \mathrm{di}$ - and trisyllabic consonant initial words with a phonological structure different from that of CVCV or CVCVCV target words. Non-word counterparts were $24 \mathrm{CVCV}$ and 24 CVCVCV, along with 48 consonant-initial words made of two and three syllables with a different phonological structure than the target words. Primes for the word and nonword distracters were constructed with the same criteria as used for the target words. Three-quarters of all trials were phonologically related (through vowels, consonants

Table 3

Example for a CVCV and a CVCVCV stimulus, with phonetic transcription of the target word, meaning, and corresponding primes. Percentage of phoneme overlap between the target and the prime are indicated in brackets (Experiment 3 ).

\begin{tabular}{|c|c|c|c|c|c|c|c|}
\hline & \multicolumn{3}{|c|}{ Target word } & \multirow{2}{*}{$\begin{array}{l}\text { Consonant related } \\
\text { кево }(75 \%)\end{array}$} & \multirow{2}{*}{$\begin{array}{l}\text { Vowel related } \\
\text { даво }(75 \%)\end{array}$} & \multirow{2}{*}{$\begin{array}{l}\text { Rhyme related } \\
\text { деко (50\%) }\end{array}$} & \multirow{2}{*}{$\begin{array}{c}\text { Unrelated } \\
\operatorname{de} ø(0 \%)\end{array}$} \\
\hline CVCV & carreau & каво & tile & & & & \\
\hline CVCVCV & cinéma & sinema & cinema & synøma (66\%) & timema (66\%) & tymøma (33\%) & tymøbe (0\%) \\
\hline
\end{tabular}


and/or rhyme only) and a quarter were not. This was the case for word and non-words targets.

All the auditory stimuli were recorded in a new recording session by the same native speaker of French as in Experiment 1, in the same conditions.

\section{Procedure}

The procedure was identical to that of Experiment 1, except that four lists were created instead of three, as four priming conditions were used. All factors were counterbalanced across participants.

\section{Results and discussion}

Only the target words were analyzed (CVCV and CVCVCV words) similarly to Experiment 1. No word reached the $33 \%$ error cut-off (mean error rate: $2.4 \%$; range: $0-12.5)$. Prior to the ANOVA, incorrect responses (2.45\%) and RTs greater than 2.5 standard deviations around the grand mean were rejected $(1.60 \%)$ as well as RTs greater than 2.5 standard deviations around individual means (1.25\%).

The analyses of the error rates showed a main effect of priming condition $\left(F_{1}(3,117)=5.42, p=.001, \quad \eta^{2}=0.12\right.$; $\left.F_{2}(3,138)=5.11, p=.002, \eta^{2}=0.10\right)$ and a significant interaction between priming condition and length (di- vs. trisyllabic) by subjects only $\left(F_{1}(3,117)=2.86, p=.04, \eta^{2}=0.07\right.$; $\left.F_{2}(3,138)=1.91, p=.13, \eta^{2}=0.04\right)$. Pairwise comparisons with Holm-Bonferroni correction (for 6 single comparisons: smallest $p$-value $<.0083$; 2nd $p$-value $<.01$, 3rd $p$-value $<.0125$, 4th $p$-value $<.0167$, 5th $p$-value $<.025$, and 6 th $p$-value $<.05)$ within CVCV words revealed that unrelated primes elicited significantly higher error rates $(7.08 \%)$ than vowel-related primes $(0.42 \%), t_{1}(39)=3.57, p<.001$, Cohen's $d=0.56 ; t_{2}(23)=3.24, p=.003$, Cohen's $\left.d=0.66\right)$. No other comparisons reached significance (second smallest $p$-value >.01). Within CVCVCV words, there were no significant differences in accuracy between priming conditions (all ps > .15)

The ANOVA on RTs included priming condition (consonant-related, vowel-related, rhyme-related and unrelated) and length (di- vs. trisyllabic) as within-subject factors. It revealed a main effect of length $\left(F_{1}(1,39)=74.72, p<.001\right.$, $\left.\eta^{2}=.66 ; \quad F_{2}(1,46)=6.49, \quad p=.01, \quad \eta^{2}=.12\right)$, as CVCVCV words $(M=760 \mathrm{~ms})$ were responded to more slowly than CVCV words $(M=724 \mathrm{~ms})$. This difference is likely to be related to the difference in the durations of the words, as CVCV words were, on average, $611 \mathrm{~ms}$ long and CVCVCV words $774 \mathrm{~ms}(t(46)=8.62, p<.001$, Cohen's $d=2.54)$.

The effect of priming condition was also significant $\left(F_{1}(3,117)=212.30, p<.001, \eta^{2}=0.84 ; F_{2}(3,138)=129.56\right.$, $p<.001, \eta^{2}=0.74$ ). Follow-up pairwise comparisons (with Holm-Bonferroni correction) revealed that words preceded by unrelated primes were responded to more slowly $(M=838 \mathrm{~ms})$ than targets preceded by (a) rhyme-related primes $\left(M=736 \mathrm{~ms}, \quad t_{1}(39)=16.69, \quad p<.001\right.$, Cohen's $d=2.64 ; t_{2}(47)=14.50, p<.001$, Cohen's $d=2.09$ ), (b) consonant-related primes $\left(M=691 \mathrm{~ms}, t_{1}(39)=23.55, p<.001\right.$, Cohen's $d=3.72 ; t_{2}(47)=16.02, p<.001$, Cohen's $\left.d=2.31\right)$, and (c) vowel-related primes $\left(M=704 \mathrm{~ms}, t_{1}(39)=17.63\right.$, $p<.001$, Cohen's $d=2.79 ; t_{2}(47)=14.55, p<.001$, Cohen's $d=2.10$ ). Besides, both the vowel- and the consonantrelated primes produced significantly faster RTs than the rhyme-related primes (vowel-related: $t_{1}(39)=5.30$, $p<.001$, Cohen's $d=0.84 ; t_{2}(47)=3.90, p<.001$, Cohen's $d=0.56$; consonant-related: $t_{1}(39)=7.13, p<.001$, Cohen's $d=1.13 ; t_{2}(47)=5.25, p<.001$, Cohen's $\left.d=0.76\right)$. The consonant-related condition did show a significant facilitation compared to the vowel-related condition by subject only $\left(t_{1}(39)=2.04, \quad p=.048, \quad\right.$ Cohen's $d=0.32 ; \quad t_{2}(47)=1.27$ $p=.21$, Cohen's $d=0.18$ ).

Finally, the interaction between length and priming condition was significant in the subject analysis only $\left(F_{1}(3,117)=2.90, \quad p=.04, \quad \eta^{2}=0.07 ; \quad F_{2}(3,138)=1.61\right.$, $\left.p=.19, \eta^{2}=0.03\right)$. Fig. 2 shows the means for each priming condition, CVCV and CVCVCV separately. To explore this interaction, we conducted separate analyses of priming condition for CVCV and CVCVCV target words.

\section{CVCV words}

The effect of priming condition was significant $\left(F_{1}(3,117)=114.00, \quad p<.001, \quad \eta^{2}=0.74 ; \quad F_{2}(3,69)=64.4\right.$, $\left.p<.001, \eta^{2}=0.74\right)$, with pairwise analyses revealing significantly slower RTs with unrelated primes $(M=827 \mathrm{~ms})$ than (a) rhyme-related primes $\left(M=718 \mathrm{~ms}, t_{1}(39)=\right.$ $11.48, p<.001$, Cohen's $d=1.81 ; t_{2}(23)=10.92, p<.001$, Cohen's $d=2.09)$, (b) vowel-related primes $(M=676 \mathrm{~ms}$, $t_{1}(39)=14.89, p<.001$, Cohen's $d=2.35 ; t_{2}(23)=12.00$, $p<.001$, Cohen's $d=2.45)$ and (c) consonant-related primes $\left(M=673 \mathrm{~ms}, \quad t_{1}(39)=16.07, \quad p<.001\right.$, Cohen's $d=2.54 ; t_{2}(23)=10.52, p<.001$, Cohen's $\left.d=2.15\right)$. Voweland consonant-related primes elicited significantly faster RTs than rhyme-related primes (vowel-related: $t_{1}(39)=4.74, p<.001$, Cohen's $d=0.75 ; t_{2}(23)=3.09$, $p=.001, \quad$ Cohen's $d=0.63 ; \quad$ consonant-related: $t_{1}(39)=4.83, \quad p<.001$, Cohen's $d=0.76 ; \quad t_{2}(23)=2.96$ $p=.007$, Cohen's $d=0.60)$. However, there was no difference between vowel- and consonant-related priming $\left(t_{1}(39)<1 ; t_{2}(23)<1\right)$.

\section{CVCVCV words}

The effect of priming condition was significant $\left(F_{1}(3,117)=109.00, \quad p<.001, \eta^{2}=0.74 ; \quad F_{2}(3,69)=67.25\right.$, $\left.p<.001, \eta^{2}=0.74\right)$. Pairwise analyses show again significantly slower RTs after unrelated primes $(M=848 \mathrm{~ms})$ than after (a) rhyme-related primes $(M=754 \mathrm{~ms}$, $t_{1}(39)=12.59, \quad p<.001$, Cohen's $d=1.99 ; \quad t_{2}(23)=9.64$ $p<.001$, Cohen's $d=1.97$ ), (b) vowel-related primes $\left(M=732 \mathrm{~ms}, \quad t_{1}(39)=12.31, p<.001\right.$, Cohen's $d=1.94$; $t_{2}(23)=9.19, p<.001$, Cohen's $\left.d=1.87\right)$ and (c) consonant-related primes $\left(M=708 \mathrm{~ms}, t_{1}(39)=16.54, p<.001\right.$, Cohen's $\quad d=2.61 ; \quad t_{2}(23)=12.29, \quad p<.001$, Cohen's $d=2.51)$. Vowel- and consonant-related primes elicited significantly faster RTs than rhyme-related primes (vowel-related: $t_{1}(39)=2.61, \quad p=.01$, Cohen's $d=0.41$; $t_{2}(23)=2.41, p=.02$, Cohen's $d=0.49$; consonant-related: $t_{1}(39)=5.96, p<.001$, Cohen's $d=0.94 ; \quad t_{2}(23)=4.77$, $p<.001$, Cohen's $d=0.97)$. Importantly, the difference between vowel- and consonant-related primes was also significant $\left(t_{1}(39)=2.90, \quad p=.006\right.$, Cohen's $d=0.46$; $t_{2}(23)=2.171, p=.04$, Cohen's $\left.d=0.44\right)$, with faster response times in the consonant-related condition. 


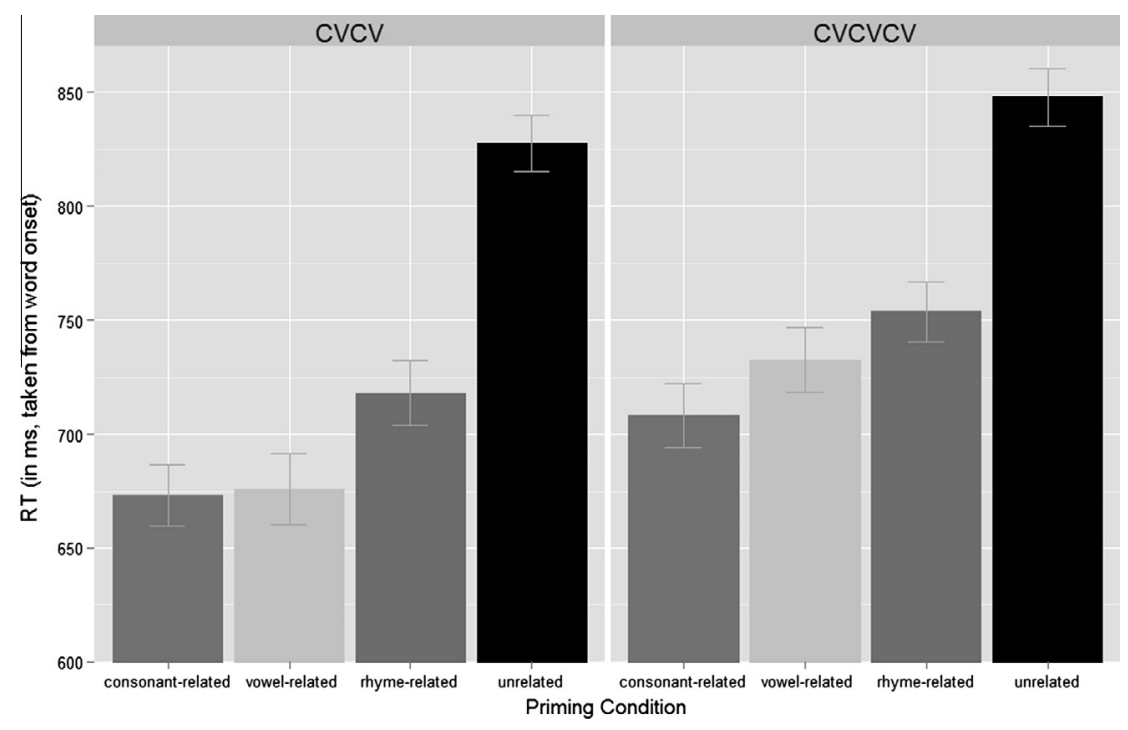

Fig. 2. Consonant, vowel and rhyme RTs (in ms) for French CVCV and CVCVCV words in Experiment 3.

To summarize, in Experiments 1 and 2, we found a consonant bias in all tested stimuli apart from iambic-like French CVCV and iambic English CVCV words, where vowels primed words equally (English) or more (French) than consonants. We suggested that this effect might be due to rhyme priming, as these CVCV words happened to be the only ones in which vowel-related primes also preserved the rhyme. In Experiment 3, we tested whether we could observe the consonant bias in these CVCV words when neutralizing the effect of the rhyme or final rime. To do so, we ensured that both consonant- and vowel-related priming conditions had a final syllable overlap with the target. However, because we anticipated that this manipulation would lead to primes and targets sharing too many phonemes for modulated effects to emerge (only one changed phoneme), we also included CVCVCV words in which primes and targets would be acoustically and phonemically more distant (and would have two changed phonemes as was the case in Experiment 1).

The results of Experiment 3 show a graded priming effect in the predicted directions. First, as predicted from previous studies showing rhyme priming in monosyllabic words (Radeau et al., 1995; Slowiaczek et al., 2000), we found a final syllable (which included the rhyme) priming effect, with CVCV and CVCVCV words being processed faster when preceded by a non-word prime sharing their final syllable than a totally unrelated prime.

Second, we found a clear priming advantage for consonants compared to vowels when the rhyme effect is neutralized. However, this effect was only found in CVCVCV words. In CVCV words, consonant and vowel priming were no different from one another, presumably due to the large overlap between primes and targets in those words (only one changed phoneme, compared to two for the CVCVCV words) which might have prevented modulation between priming conditions. It should be noted that the CVCVCV stimuli are more comparable to those of CVCV used in the previous experiments, as in both cases primes were differentiated by two phonemes.
Finally, it must be noted that priming effects overall were larger in this third experiment (around $125 \mathrm{~ms}$ ) than in the previous ones (around $50 \mathrm{~ms}$ ). This could be explained by the higher relatedness proportion (RP) used in this experiment: here, $75 \%$ of the targets were phonologically related to the primes against $67 \%$ in Experiments 1 and 2 . It has been established that increasing RP usually results in larger priming effects (e.g., Hutchison, Neely, \& Johnson, 2001; Neely, 1977), possibly due to a greater involvement of attentional mechanisms (strategic priming as opposed to automatic priming). However this only tends to be found with relatively long SOAs (e.g., Hutchison et al., 2001). As we used a $10 \mathrm{~ms}$ SOA throughout this study, it seems unlikely that the increase in RP could result in an increase of strategic priming, and therefore, to a larger priming effect overall. Having said this, it remains possible that the high proportion of trials in which both primes and targets shared the rhyme (3/4) could have contributed to enhance participants' global attention towards rhyme processing, accentuating the weight of rhyme priming effects across all phonologically related trials. However, it does not undermine the main finding that in CVCVCV words consonant-sharing primes are processed faster than vowel-sharing primes when the rhyme is held constant. Implications of the present findings for interpreting Experiments 1 and 2, together with a second complementary explanation for the lack of consonant bias in CVCV words, are further discussed below.

\section{General discussion}

Following the proposal by Nespor et al. (2003) of an asymmetry in the role of consonants and vowels in lexical processing, three experiments evaluated the contribution of preserved consonantal and vocalic phonemes using an online auditory priming method. A cross-linguistic approach was adopted in Experiments 1 (French) and Experiment 2 (English) to explore in adulthood the differences 
observed for French and English in the developmental literature. Based upon the findings of these first two experiments, Experiment 3 was designed to examine consonantand vowel-related priming in the context of rhyme overlap priming.

For Experiments 1 and 2, the results confirm the general observation of a facilitatory effect when the target shared the consonant tier with its prime, in line with previous adult literature that mostly focused on visually-presented stimuli, or used offline auditory tasks. The effect of vowels, however, reveals a more complex pattern than observed in previous adult experiments so far. Indeed, while no vocalic priming was found for VCVC words in both languages and in trochaic CVCV words in English (resulting in a consonant bias in these conditions), preserving the vocalic tier cued faster word recognition than the control unrelated condition, mainly for CVCV words in French (resulting in an unpredicted vocalic bias), and to a lesser extent in iambic CVCV English words (resulting in no bias). These results stand in sharp contrast to those obtained in visual priming experiments since so far only non-facilitatory (see among others, Duñabeitia \& Carreiras, 2011; Carreiras, Vergara \& Perea, 2009; Lupker et al., 2008; New et al., 2008; Perea \& Lupker, 2004) or even inhibitory effects (New \& Nazzi, in press) had been observed for vowels.

Following these findings, we considered different factors to account for the unpredicted performance with iambic-like CVCV French words and iambic CVCV English words. First, we argued that intelligibility of the primes and syllabification/ambisyllabicity could not explain the present pattern of results. Second, we discussed how rhyme priming, which appears specific to the auditory modality, might explain the unexpected priming of vowel-related primes in these iambic(-like) CVCV words. Indeed, previous auditory priming studies had revealed the importance of the overlap of final phonemes (including the word rhyme) in spoken word recognition (Dumay \& Radeau, 1997; Dumay et al., 2001; Emmorey, 1989; Radeau, 1995; Radeau et al., 1995; Slowiaczek et al., 2000). We discussed how interpreting our findings in terms of rhyme priming would predict the pattern of results found in Experiments 1 and 2, in which vowel priming was only found in cases where the rhyme was preserved between the target and the primes, that is, both iambic-like CVCV French words and iambic CVCV English words.

Experiment 3 explored this interpretation, testing French adults with words having the same structure (CVCV and (VCVCV) as the ones for which we had found vowel priming and a vocalic bias in Experiment 1. Our results first show that preserving only the last syllable (which included the rhyme) between the prime and the target facilitates word recognition, in line with the results cited above. Second, in these conditions we were able to observe the expected advantage of consonant tier preservation over vowel tiers, at least in CVCVCV words. This effect, in retrospect, indicates that the vocalic priming effect observed in French and English iambic CVCV words was likely to be mostly due to a rhyme priming effect than that of vowels priming per se.

Thus, the most parsimonious explanation for the pattern of results across the three experiments is that there are two coexisting biases in auditory processing, a consonant bias and rhyme bias, and that these act additively in the present priming task. This would predict a consonant bias in all stimuli except where there was a rhyme overlap between prime and target, where the bias is neutralized by the rhyme overlap priming. This hypothesis accounts for most of our findings, with one exception being the lack of robust consonant priming for French CVCV stimuli in Experiments 1 and 3. In Experiment 1 the use of these stimuli led to a significant vowel bias, while in Experiment 3 no consonant bias was found even when rhyme overlap was controlled. To explain these exceptions to the general pattern of consonant priming we need to go beyond our empirical observations, and propose a tentative explanation regarding the locus of the consonant bias in the course of lexical activation. Discussing their results in the visual modality, New and Nazzi (in press) recently suggested that the consonant bias in the written modality could be explained by skeleton-shared neighborhoods which may cue differences across experimental conditions, or even languages. The shared-vowel skeleton represents the number of words that can be built with the sequence of vowels shared by the prime and the target (and the same goes for the consonant skeleton). How could the consonant bias be mediated by shared neighborhood effects? One possibility is that these skeleton values indicate how informative partly related primes are. For example, the word otage (/ ota3/, meaning hostage) has only two consonant skeleton neighbors (/-t-3/, in étage /eta3/, meaning floor and in attiger /atize/, a very low frequency colloquial word meaning to exaggerate), but there are twelve neighbors with the same vowel skeleton (/o-a-/, e.g., hommasse, opaque, homard, etc. - meaning respectively butch, opaque and lobster). In this example, a prime with the consonant skeleton |-t-3| can only activate three words, otage and its two neighbors, while a prime with the vowel skeleton /o-a-/ will activate 13 words, and is therefore less informative. If test words happen to have vowel skeletons with larger neighborhoods than consonant skeletons, this could translate into less priming from vowel-related primes than consonant-related primes. Alternatively, a larger skeleton neighborhood could turn a non-word prime into a more word-like sequence, thus increasing the activation of its corresponding word in the lexicon. In this perspective, a prime with a larger neighborhood would lead to faster recognition of the target word. Since New and Nazzi (in press) found that consonant-related primes were more effective than vowel-related primes, and that consonant skeleton neighborhoods were smaller than vowel skeleton neighborhoods, their findings support the first proposal that the larger the shared neighborhoods, the smaller the priming effect.

Looking back at our French and English stimuli in Experiments 1-3, we established that, as in New and Nazzi (in press), the majority of our selected words have less consonant skeleton neighbors than vowel neighbors (see Table 4). This difference might explain the overall consonant advantage: smaller consonant skeleton neighborhoods might be more informative than larger vowel skeleton neighborhoods, resulting in a larger consonant priming effect. The only exception to this disparity in neighborhood was in the French CVCV target words used 
in Experiments 1 and 3. In this case the lack of skeleton imbalance would predict the observed null effect in the absence of rhyme overlap (Experiment 3), and the vowel bias we found when the rhyme is preserved between the vowel-related prime and the target (Experiment 1). Therefore, our findings appear to be fully explained by the combined effects of a consonant bias based on an imbalance in consonant versus vowel skeleton neighborhoods, and a rhyme bias.

At this point, we would like to discuss potential implications of our findings to models of lexical access, both in terms of the consonant bias and rhyme overlap effect. With the exception of New and Nazzi (in press), little attempt has been made to integrate the consonant bias in models of either written word recognition (e.g., SOLAR, Davis, 2010; open-bigram model, Grainger, Granier, Farioli, Van Assche, \& van Heuven, 2006) or spoken word recognition. The PARSYN model of spoken word recognition, based on neighborhood activation (Luce, Goldinger, Auer, \& Vitevitch, 2000), posits that phonological similarity between a prime and its target usually leads to inhibition (see for experimental evidence Goldinger, Luce, Pisoni, \& Marcario, 1992; Magnuson, Dixon, Tanenhaus, \& Aslin, 2007; Peereman \& Content, 1995), but this is because the aforementioned studies used real words as primes and targets, suggesting inhibition at the lexical level, in agreement with the NAM (Luce \& Pisoni, 1998) or Cohort models (MarslenWilson, 1987). With non-words as primes, the time course of activation might be different. Because non-words are unlikely to be mistaken for words and then fully activate word candidates, the activation of the potential target word is contained at the phonological or pre-lexical levels, where activation is always facilitatory. Interestingly, a recent paper by Mayor and Plunkett (2014) replicated the consonant-vowel asymmetry in a TRACE model implemented on infants' lexicon, with the consonant bias arising from cohort and neighborhood competition in an expanding lexicon. Another way of accounting for the consonant bias could be that phonemes do not exclusively project activation in isolation, but that phoneme tiers, or skeletons, also activate the network. Primes with fewer skeletons, usually consonant skeletons, would activate fewer words that receive comparatively more activation than primes with more skeleton neighbors. As a consequence low skeleton neighbors are more pre-activated and this advantage translates into the consonant advantage.

Models of spoken word recognition should likewise account for the facilitatory rhyme overlap, although Cohort models have argued for a crucial role of the initial phoneme in visual word recognition (and see Frauenfelder, Scholten, \& Content, 2001 for investigation of positional effects within words). Models based on probabilities such as Shortlist B (Norris \& McQueen, 2008) or TRACE (McClelland \& Elman, 1986) where processing stages are not so strictly hierarchical (Allopenna, Magnuson, \& Tanenhaus, 1998; McQueen, Dahan, \& Cutler, 2003) are better candidates to explain how non-words prime the recognition of real words, and as such might be better at accounting for the rhyme overlap effects.

Another goal of the study was to provide a controlled cross-linguistic comparison of the consonant/vowel asymmetry. The two languages tested, French and English, were selected because they have been found to lead to contrasted results in the developmental literature (see Floccia et al., in press; Havy \& Nazzi, 2009; Nazzi, 2005) and their linguistic properties vary. For example, their consonantvowel ratios are different, with a more balanced ratio in French than in English, which would predict a larger consonant bias for lexical processing in English (albeit contrary to the infant data). However, our findings do not reveal much of a modulation of priming by language. On the contrary, listeners in the two languages showed strikingly similar behaviors, although in English stress was a modulating factor (which could not occur in French due to the absence of lexical stress in this language). Therefore, although the onset of the consonant bias in lexical processing in the course of language development reveals important differences between children learning French and English, adult data suggest a strong similarity in auditory processing in adulthood, supporting the original Nespor et al. (2003) claim that the consonant bias at the lexical level is language-general.

In conclusion, the present experiments provide some answers regarding the universality of the consonantal bias proposed by Nespor et al. (2003), supporting the view that in spoken word processing, consonants have an overall privileged role over vowels at the phonological level, in French and English, the two languages tested here. This is the first demonstration of the consonant advantage in an online auditory task, reinforcing the phonological interpretation suggested for the bias which had been found in the visual modality (New \& Nazzi, in press; New et al., 2008). More research is necessary to get a fuller comprehension of the factors that can contribute to the consonant/vowel asymmetry, such as the acoustic/phonological properties of the phonemes involved or the skeleton neighbors, and modulate these effects, such as the rhyme bias we uncovered. This should help determine what leads consonants to

Table 4

Consonant and vowel skeleton neighborhood, split by word category (Experiment 1, 2 and 3).

\begin{tabular}{|c|c|c|c|c|c|c|}
\hline Language & Structure & Stress & C-skeleton & V-skeleton & $t$ & $p$ \\
\hline \multirow{2}{*}{ French (Exp. 1) } & CVCV & - & 45.33 & 56.17 & $<1$ & n.s. \\
\hline & VCVC & - & 12.29 & 34.62 & 3.41 & .001 \\
\hline \multirow[t]{4}{*}{ English (Exp. 2) } & CVCV & Trochaic & 11.06 & 189.19 & 4.13 & $<.001$ \\
\hline & & Iambic & 11.20 & 87.70 & 4.27 & $<.001$ \\
\hline & VCVC & Trochaic & 14.80 & 317.13 & 4.59 & $<.001$ \\
\hline & & Iambic & 16.65 & 63.00 & 6.11 & $<.001$ \\
\hline \multirow[t]{2}{*}{ French (Exp. 3) } & CVCV & - & 45.33 & 56.17 & $<1$ & n.s. \\
\hline & CVCVCV & - & 14.75 & 61.42 & 30.04 & $<.001$ \\
\hline
\end{tabular}


be reliable cues for lexical access, while vowels hinder or facilitate processing depending on the paradigm and the age of the listeners.

\section{Acknowledgments}

The first and second authors contributed equally to this study. The authors would like to thank the reviewers for their stimulating comments. This work was funded by joint ESRC/ANR grants awarded to Caroline Floccia and Jeremy Goslin by the ESRC (ES/H040927/1) and Thierry Nazzi by the ANR (ANR-09-FRBR-015) and by LABEX EFL (ANR CGI).

\section{A. Supplementary material}

Supplementary data associated with this article can be found, in the online version, at http://dx.doi.org/10.1016/ j.jml.2013.12.001.

\section{References}

Acha, J., \& Perea, M. (2010). Does kaniso activate CASINO? Input coding schemes and phonology in visual-word recognition. Experimental Psychology, 57, 245-251.

Allopenna, P. D., Magnuson, J. S., \& Tanenhaus, M. K. (1998). Tracking the time course of spoken word recognition using eye movements: Evidence for continuous mapping models. Journal of Memory and Language, 38, 419-439.

Baayen, R. H., Piepenbrock, R., \& Gulikers, L. (1995). The CELEX lexical database. Philadelphia, PA: University of Pennsylvania, Linguistic Data Consortium.

Bedoin, N., \& Krifi, S. (2009). The complexity of phonetic features organisation in reading. In F. Pellegrino, E. Marsico, I. Chitoran, \& C. Coupé (Eds.), Approaches to phonological complexity. Mouton de Gruyter.

Berent, I., \& Perfetti, C. A. (1995). A rose is a REEZ: The two-cycles model of phonology assembly in reading English. Psychological Review, 102$184,146$.

Bleses, D., Basbøll, H., Lum, J., \& Vach, W. (2010). Phonology and lexicon in a cross-linguistic perspective: The importance of phonetics - A commentary on Stoel-Gammon's 'Relationships between lexical and phonological development in young children'. Journal of Child Language, 1-8.

Bonatti, L. L., Peña, M., Nespor, M., \& Mehler, J. (2005). Linguistic constraints on statistical computations. Psychological Science, 16, 451-459.

Bonatti, L. L., Peña, M., Nespor, M., \& Mehler, J. (2007). On consonants, vowels, chickens, and eggs. Psychological Science, 18, 924-925.

Caramazza, A., Chialant, D., Capasso, R., \& Miceli, G. (2000). Separable processing of consonants and vowels. Nature, 403, 428-430.

Carré, R. (2009). Dynamic properties of an acoustic tube: Prediction of vowel systems. Speech Communication, 51, 26-41.

Carreiras, M., \& Price, C. J. (2008). Brain activation for consonants and vowels. Cerebral Cortex, 18, 1727-1735. http://dx.doi.org/10.1093/ cercor/bhm202.

Carreiras, M., Vergara, M., \& Perea, M. (2009). ERP correlates of transposed-letter similarity effects: Are consonants processed differently from vowels? Neuroscience Letters, 419, 219-224.

Columbo, L., Zorzi, M., Cubelli, R., \& Brivio, C. (2003). The status of consonants and vowels in phonological assembly: Testing the twocycle model with Italian. The European Journal of Cognitive Psychology, $15,405-433$.

Creel, S. C. (2012). Phonological similarity and mutual exclusivity: On-line recognition of atypical pronunciations in 3-5-year-olds. Developmental Science, 15, 697-713.

Creel, S. C., Aslin, R. N., \& Tanenhaus, M. K. (2006). Acquiring an artificial lexicon: Segment type and order information in early lexical entries. Journal of Memory and Language, 54, 1-19.

Creel, S. C., Tanenhaus, M. K., \& Aslin, R. N. (2006). Consequences of lexical stress on learning an artificial lexicon. Journal of Experimental Psychology: Learning, Memory and Cognition, 32, 15-32.

Cutler, A., \& Carter, D. M. (1987). The predominance of strong initial syllables in the English vocabulary. Computer Speech and Language, 2, 133-142.
Cutler, A., Sebastián-Gallés, N., Soler-Vilageliu, O., \& van Ooiken, B. (2000) Constraints of vowels and consonants on lexical selection: Crosslinguistic comparisons. Memory \& Cognition, 28, 746-755.

Davis, C. J. (2005). N-Watch: A program for deriving neighborhood size and other psycholinguistic statistics. Behavior Research Methods, 37, $65-70$.

Davis, C. J. (2010). The spatial coding model of visual word identification. Psychological Review, 117, 713-758. http://dx.doi.org/10.1037/ a0019738.

Dumay, N., Benraïss, A., Barriol, B., Colin, C., Radeau, M., \& Besson, M. (2001). Behavioral and electrophysiological study of phonological priming between bisyllabic spoken words. Journal of Cognitive Neuroscience, 13, 121-143.

Dumay, N., \& Radeau, M. (1997). Rime and syllabic effects in phonological priming between French spoken words. Paper presented at the Eurospeech. University of Patras.

Duñabeitia, J. A., \& Carreiras, M. (2011). The relative position priming effect depends on whether letters are vowels or consonants. Journal of Experimental Psychology: Learning, Memory and Cognition, 37, $1143-1163$.

Emmorey, K. D. (1989). Auditory morphological priming in the lexicon. Language and Cognitive Processes, 4, 73-92.

Ferreres, A. R., López, C., \& China, N. N. (2003). Phonological alexia with vowel-consonant dissociation in non-word reading. Brain $\mathcal{E}$ Language, $\quad 84, \quad 399-413 . \quad$ http://dx.doi.org/10.1016/S0093934X(02)00559-X.

Fletcher, J., \& Vatikiotis-Bateson, E. (1994). Prosody and intrasyllabic timing in French. Working Papers in Linguistics, 43, 41-46.

Floccia, C., Goslin, J., Morais, J. J., \& Kolinsky, R. (2012). Syllable effects in a fragment-detection task in Italian listeners. Frontiers in Psychology, 3. http://dx.doi.org/10.3389/fpsyg.2012.00140.

Floccia, C., Nazzi, T., Delle Luche, C., Poltrock, S., \& Goslin, J. (in press) English-learning one- to two-year-olds do not show a consonant bias in word learning. Journal of Child Language. http://dx.doi.org/10.1017/ S0305000913000287.

Frauenfelder, U. H., Scholten, M., \& Content, A. (2001). Bottom-up inhibition in lexical selection: Phonological mismatch effects in spoken word recognition. Language and Cognitive Processes, 16, 583-607.

Goldinger, S. D., Luce, P. A., Pisoni, D. B., \& Marcario, J. K. (1992). Formbased priming in spoken word recognition: The roles of competition and bias. Journal of Experimental Psychology: Learning, Memory and Cognition, 18, 1211-1238.

Goslin, J., \& Floccia, C. (2007). Comparing French syllabification in preliterate children and adults. Applied Psycholinguistics, 28, 341-367.

Grainger, J., \& Ferrand, L. (1994). Phonology and orthography in visual word recognition: Effects of masked homophone primes. Journal of Memory and Language, 33, 218-233.

Grainger, J., \& Ferrand, L. (1996). Masked orthographic and phonological priming in visual word recognition and naming: Cross-task comparisons. Journal of Memory and Language, 35, 623-647.

Grainger, J., Granier, J.-P., Farioli, F., Van Assche, E., \& van Heuven, W. J. B. (2006). Letter position information and printed word perception: The relative-position priming constraint. Journal of Experimental Psychology: Human, Perception and Performance, 32, 865-884.

Havy, M., Bertoncini, J., \& Nazzi, T. (2011). Word learning and phonetic processing in preschool age children. Journal of Experimental Child Psychology, 108, 25-43.

Havy, M., \& Nazzi, T. (2009). Better processing of consonantal over vocalic information in word learning at 16 months of age. Infancy, 14, 439-456. http://dx.doi.org/10.1080/15250000902996532.

Havy, M., Serres, J., \& Nazzi, T. (in press). A consonant/vowel asymmetry in word-form processing: Eye-tracking evidence in childhood and in adulthood. Language and Speech. http://dx.doi.org/10.1177/ 0023830913507693.

Højen, A., \& Nazzi, T. (in preparation). Language-specific phonological biases in word learning.

Holm, S. (1979). A simple sequentially rejective multiple test procedure. Scandinavian Journal of Statistics, 6, 65-70.

Hooper, J. B. (1972). The syllable in phonological theory. Language, 48, $525-540$.

Hutchison, K. A., Neely, J. H., \& Johnson, J. D. (2001). With great expectations, can two "wrongs" prime a "right"? Journal of Experimental Psychology: Learning, Memory, and Cognition, 27, 1451-1463.

Jun, S.-A., \& Fougeron, C. (2002). Realizations of accentual phrase in French intonation. Probus, 14, 147-172.

Kahn, D. (1976). Syllable-based generalizations in English phonology. Bloomington, IN: Indiana University Linguistics Club. 
Keuleers, E., Lacey, P., Rastle, K., \& Brysbaert, M. (2012). The British Lexicon Project: Lexical decision data for 28,730 monosyllabic and disyllabic English words. Behavior Research Methods, 44, 287-304. http://dx.doi.org/10.3758/s13428-011-0118-4.

Ladefoged, P. (2001). A course in phonetics. Boston: Heinle \& Heinle.

Lahiri, A. (2001). Metrical patterns. In E. König \& M. Haspelmath (Eds.), Language typology and language universals (pp. 1347-1367). Berlin: Mouton.

Lee, H.-W., Rayner, K., \& Pollatsek, A. (2001). The relative contribution of consonants and vowels to word identification during reading. Journal of Memory and Language, 44, 189-205.

Luce, P. A., Goldinger, S. D., Auer, E. T. J., \& Vitevitch, M. S. (2000). Phonetic priming, neighorhood activation and PARSYN. Perception $\mathcal{E}$ Psychophysics, 62, 615-625.

Luce, P. A., \& Pisoni, D. B. (1998). Recognizing spoken words: The neighborhood activation model. Ear and Hearing, 19, 1-36.

Lupker, S. J., Perea, M., \& Davis, C. J. (2008). Transposed-letter effects: Consonants, vowels and letter frequency. Language and Cognitive Processes, 23, 93-116. http://dx.doi.org/10.1080/ 01690960701579714.

Maddieson, I. (1984). Patterns of sounds. Cambridge: Cambridge University Press.

Magnuson, J. S., Dixon, J. A., Tanenhaus, M. K., \& Aslin, R. N. (2007). The dynamics of lexical competition during spoken word recognition. Cognitive Science, 31, 133-156.

Mani, N., \& Plunkett, K. (2007). Phonological specificity of vowels and consonants in early lexical representations. Journal of Memory and Language, 57, 252-272.

Mani, N., \& Plunkett, K. (2008). Fourteen-month-olds pay attention to vowels in novel words. Developmental Science, 11, 53-59.

Marslen-Wilson, W. D. (1987). Functional parallelism in spoken-word recognition. Cognition, 25, 71-102.

Mayor, J., \& Plunkett, K. (2014). Infant word recognition: Insights from TRACE simulations. Journal of Memory and Language, 71, 89-123, http://dx.doi.org/10.1016/j.jml.2013.09.009.

McClelland, J. L., \& Elman, J. L. (1986). The TRACE model of speech perception. Cognitive Psychology, 18, 1-86.

McQueen, J. M., Dahan, D., \& Cutler, A. (2003). Continuity and gradedness in speech processing. In N. O. Schiller \& A. S. Meyer (Eds.), Phonetics and phonology in language comprehension and production: Differences and similarities (pp. 39-78). Berlin: Mouton de Gruyter.

Nazzi, T. (2005). Use of phonetic specificity during the acquisition of new words: Differences between consonants and vowels. Cognition, 98, $13-30$.

Nazzi, T., \& Bertoncini, J. (2009). Phonetic specificity in early lexical acquisition: New evidence from consonants in coda positions. Language and Speech, 52, 463-480.

Nazzi, T., Floccia, C., Moquet, B., \& Butler, J. (2009). Bias for consonantal information over vocalic information in 30-month-olds: Crosslinguistic evidence from French and English. Journal of Experimental Child Psychology, 102, 522-537.

Nazzi, T., Havy, M., Polka, L., Delle Luche, C., Floccia, C., \& Højen, A. (2011). Crosslinguistic study of the consonantal bias in early word learning. Paper presented at the SRCD biennial meeting, Montreal.

Nazzi, T., \& New, B. (2007). Beyond stop consonants: Consonantal specificity in early lexical acquisition. Cognitive Development, 22, 271-279.

Neely, J. H. (1977). Semantic priming and retrieval from lexical memory: Roles of inhibitionless spreading activation and limited-capacity attention. Journal of Experimental Psychology: General, 106, 226-254.

Nespor, M., Peña, M., \& Mehler, J. (2003). On the different roles of vowels and consonants in speech processing and language acquisition. Lingue e Linguaggio, 2, 203-229.

New, B., Araújo, V., \& Nazzi, T. (2008). Differential processing of consonants and vowels in lexical access through reading. Psychological Science, 19, 1223-1227.
New, B., \& Nazzi, T. (in press). The time course of consonant and vowel processing during word recognition. Language and Cognitive Processes. http://dx.doi.org/10.1080/01690965.2012.735678.

New, B., \& Pallier, C. (2001). LEXIQUE toolbox. <http://www.lexique.org/ toolbox.pub/> Retrieved 02.11.12.

New, B., Pallier, C., Ferrand, L., \& Matos, R. (2001). Une base de données lexicales du français contemporain sur internet: LEXIQUETM. L'Année Psychologique, 101, 447-462.

Newport, E. L., \& Aslin, R. N. (2004). Learning at a distance. I. Statistical learning of non-adjacent dependencies. Cognitive Psychology, 48, 127-162.

Norris, D., \& McQueen, J. M. (2008). Shortlist B: A Bayesian model of continuous speech recognition. Psychological Review, 115, 357-395.

Peereman, R., \& Content, A. (1995). Neighborhood size effect in naming: Lexical activation or sublexical correspondences? Journal of Experimental Psychology: Learning, Memory and Cognition, 21, 409-421.

Perea, M., \& Carreiras, M. (2006). Do transposed-letter similarity effects occur at a syllable level? Experimental Psychology, 53, 308-315.

Perea, M., \& Lupker, S. J. (2004). Does caniso activate casino? Transposedletter similarity effects with nonadjacent letter positions. Journal of Memory and Language, 51, 231-246.

Pulgram, E. (1970). Syllable, word, nexus, cursus. The Hague: Mouton.

Radeau, M. (1995). Facilitation and inhibition in phonological priming. Paper presented at the 36th annual meeting of the psychonomics society, Los Angeles.

Radeau, M., Morais, J., \& Segui, J. (1995). Phonological priming between monosyllabic spoken words. Journal of Experimental Psychology: Human, Perception and Performance, 21, 1297-1311.

Repp, B. H. (1984). Categorical perception: Issues, methods, findings. In N. J. Lass (Ed.). Speech and language: Advances in basic research and practice (Vol. 10, pp. 243-335). New York: Academic Press.

Sebastián-Gallés, N., Dupoux, E., Segui, J., \& Mehler, J. (1992). Contrasting syllabic effects in Catalan and Spanish. Journal of Memory and Language, 31, 18-32.

Sharp, D. J., Scott, S. K., Cutler, A., \& Wise, R. J. S. (2005). Lexical retrieval constrained by sound structure: The role of the left inferior frontal gyrus. Brain \& Language, 92, 309-319.

Slowiaczek, L. M., McQueen, J. M., Soltano, E. G., \& Lynch, M. (2000). Phonological representations in prelexical speech processing: Evidence from form-based priming. Journal of Memory and Language, 43, 530-560.

Stilp, C. E., \& Kluender, K. R. (2010). Cochlea-scaled entropy, not consonants, vowels, or time, best predicts speech intelligibility. PNAS, 107, 12387-12392.

Toro, J. M., Nespor, M., Mehler, J., \& Bonatti, L. L. (2008). Finding words and rules in a speech stream. Functional differences between vowels and consonants. Psychological Science, 19, 137-144.

Trammell, R. L. (1993). English ambisyllabic consonants and half-closed syllables in language teaching. Language Learning, 43, 311-356.

Treiman, R., Bowey, J. A., \& Bourassa, D. (2002). Segmentation of spoken words into syllables by English-speaking children as compared to adults. Journal of Experimental Child Psychology, 83, 213-238.

Treiman, R., \& Danis, C. (1988). Syllabification of intervocalic consonants. Journal of Memory and Language, 27, 87-104.

Vaissière, J. (1991). Rhythm, accentuation and final lengthening in French. In J. Sundberg, L. Nord, \& R. Carlson (Eds.), Music, language, speech and brain (pp. 108-120). Macmillan Press.

van Ooijen, B. (1996). Vowel mutability and lexical selection in English: Evidence from a word reconstruction task. Memory $\&$ Cognition, 24, 573-583.

Vergara-Martínez, M., Perea, M., Marín, A., \& Carreiras, M. (2011). The processing of consonants and vowels during letter identity and letter position assignment in visual-word recognition: An ERP study. Brain E' Language, 118, 105-117.

Zesiger, P., \& Jöhr, J. (2011). Les représentations phonologiques des mots chez le jeune enfant. Enfance, 3, 293-309. 